\title{
Population aging: What role for regional science?
}

\author{
K. Bruce Newbold 1
}

Received: 28 April 2015 / Accepted: 24 June 2015 / Published online: 15 July 2015

(C) Springer-Verlag Berlin Heidelberg 2015

\begin{abstract}
This paper is a revised version of the Western Regional Science Association Presidential Address, delivered at the 54th annual meetings of the Western Regional Science Association, Tucson, Arizona, February 17, 2015. The paper addresses population aging, an issue that has increasingly become a concern for developed and developing nations. Specifically, it considers aging in the USA and the world along with how, where and why Regional Scientists can be more engaged in this discussion.
\end{abstract}

\section{Introduction}

The population of the USA, along with the population of many other countries, is growing older, evidenced by increasing median ages or a declining share of the young relative to the old. At the national scale, the prime reason for population aging is the decline in fertility rates to levels at or below replacement levels (a total fertility rate of 2.1) and increased life expectancies owing to advances in sanitation, nutrition and medical care. At the local level, the main reason for population aging is migration, with the out-migration of young workers, for example, leaving behind older populations. In regions of the USA, Canada or Europe, this trend is illustrated by the closing of schools and libraries as young families depart in search of employment, education and lifestyle opportunities (Taber 2012). If there is in-migration into these places, it is typically insufficient to offset population loss and is often characterized by older

\footnotetext{
$\triangle \quad$ K. Bruce Newbold

Newbold@mcmaster.ca

1 School of Geography and Earth Sciences, McMaster University, 1280 Main St. West, Hamilton, ON L8S 4K1, Canada
} 
retirees returning to their place of birth, with a well-established literature that discusses the concept of return migration amongst the old to their places of birth or long-term residence (see, for example, Long 1988; Newbold 2005). The net result is economic and demographic decline aided by an older and smaller population.

Aging is not a problem unto itself: Individuals want to grow old. Overall, people are significantly healthier than in the past, enjoy longer life spans and live longer without disability. However, the aggregate effect of population aging and the concomitant unprecedented changes to the population structure of many countries pose huge challenges for their economies and their aging populations, prompting multiple questions. Will there be the capacity to support a growing number of retirees and fund long-term health care with a smaller and declining labor force? What are the economic benefits and costs of aging at the local, regional and national levels? How will aging alter the real estate market and the retail sector? Can immigration offset population aging and how will it reshape society? What other demographic or socioeconomic policies can be used to decrease the impacts of an aging society?

The magnitude and importance of these questions open opportunities for Regional Scientists to contribute their research and insight(s) for both basic and policy-relevant research. Although regional scientists have certainly contributed to the literature on aging, I would argue that there is a significant room for expansion of research agendas related to aging, the topic of this paper. Consequently, I will first talk about aging in the USA and the world, before considering how, where and why we, as Regional Scientists, can be more engaged in this discussion. Some of my thoughts and comments are derived from David Plane's 'What about Aging in Regional Science?' paper, which was presented at the 2010 NARSC meetings in Denver, Colorado (Plane 2012). Like him, I want to discuss 'aging' as a research subject of Regional Science given its importance. But, I also want to take this further to discuss not just the demographic aspects of an aging society, but what it means from a variety of different viewpoints within regional science, and offer suggestions on research implications and directions.

\section{Aging in the USA and the World}

'Agequake' (Wallace 2001). 'Baby Boom Tsunami' (Frey 2001). 'Grey Tsunami.' 'Silver Tsunami.' The 'Greying of the Population.' All of these are terms that have been used in both the academic literature and the media to describe the aging of populations around the globe, and all tend to inspire dread and fear. How, after all, do you stop a tsunami or an earthquake? You can't. But, you can prepare for them through coastal defences or building codes to reduce the risk of death and damage during a tsunami or earthquake. Likewise, we can also prepare for an aging society, and at least here we have a fairly good chance of predicting what that future society will look like from a demographic perspective.

First of all, it is probably useful to define what is meant by aging, with age 65 the usual divider between young and old largely because of its traditional link to retirement and the start of social benefits. However, aging is more than just the divide between workers and retirees, with the literature often distinguishing between the 'young elderly' and the 'old elderly,' with the most significant changes including 
major health issues, loss of independence and institutionalization occurring amongst the older elderly group, and typically after age 80. But it's not just who is already old, but who will be old in the coming years, with concomitant demographic and economic implications for society. In particular, the current baby boom cohort, or those born between 1946 and 1965, will define aging societies for years to come, particularly in countries including the USA, Canada, Australia and parts of Europe. Having already shaped their respective societies, these 'pre-seniors' will continue to shape their surrounding society in terms of politics, economics and lifestyle choices. For example, those already aged 65 or older, along with Baby Boomers, will certainly shape political decisions in the coming decades, given that voter participation increases with age, and with Americans aged 65 and over having the highest voting rates (File 2014). Consequently, policies and agendas that favor the older population may receive greater attention in coming elections.

But even within the baby boomer cohort, not all individuals are equal, with significant differences in the boomer generation where 'early boomers' can be distinguished from 'late boomers' (Green 2006). Many of the late baby boomers, or those roughly 50-60 years old (as of 2015), are still working and have different consumption patterns than their older, earlier boomer counterparts. For most in this group, retirement is still a dream and they may be more concerned with what retirement actually means, knowing that fewer workers will intensify pressures on health care and other resources. Early (and therefore older) boomers, on the other hand, are already retired and drawing social security, although some will have remained in the labor force, either out of necessity, due to changes to the start of social welfare benefits such as Social Security, or a preference for work.

Globally, only $8 \%$ of the world's population is currently aged greater than 65 , but the proportion over 65 is much greater in many regions and countries (Table 1). ${ }^{1}$ In Japan, $26 \%$ of its population is over the age of 65 , making it the oldest country when measured by the age of its population. If current population projections hold, $41 \%$ of Japan's population will be 65 or older by 2055, and its' population will have shrunk by some 37 million people. But Japan is hardly alone in facing an aging and shrinking population. In South Korea, there were 5.7 million students in elementary schools in 1980, a number that has shrunk to just three million today, reflecting dramatic declines in fertility levels (Ibbitson 2014). By 2060, South Korea's population will be older and smaller, with half of its population projected to be over 65. To quote Canada's Globe and Mail newspaper (Ibbitson 2014, p. A4) in regard to shifting demographics in South Korea: 'That's not population decline. That's population collapse.' Also in Asia, China's population is rapidly aging, driven by its one-child policy, a program which has been eased over the past decade given concerns over the country's demographic future. Elsewhere, many countries in Europe are aging rapidly. Currently, $17 \%$ of Netherland's population is 65 or over, and the proportion is even higher-approaching $20 \%$-in much of Northern Europe. In Germany, $21 \%$ are over 65, and many of the Baltic and Scandinavian countries are not far beyond. Canada's 65 plus population

\footnotetext{
1 Many of the statistics related to the proportional size of older (age $65+$ ) populations were taken from the Population Reference Bureau's 2014 World Population Data Sheet (www.prb.org).
} 
Table 1 Percent of population aged $65+$ by world selected world region and country, 2014

Source: Based on data from the Population Reference Bureau, 2014 World Population Data Sheet

\begin{tabular}{|c|c|}
\hline Region & $\%>65$ \\
\hline Africa & 4 \\
\hline Sub-Saharan Africa & 3 \\
\hline Northern Africa & 5 \\
\hline Western Africa & 3 \\
\hline Eastern Africa & 3 \\
\hline Middle Africa & 3 \\
\hline Southern Africa & 5 \\
\hline Americas & 10 \\
\hline North America & 14 \\
\hline USA & 14 \\
\hline Central America & 6 \\
\hline Caribbean & 9 \\
\hline Puerto Rico & 16 \\
\hline South America & 8 \\
\hline Argentina & 10 \\
\hline Asia & 7 \\
\hline Western Asia & 5 \\
\hline Central Asia & 5 \\
\hline South Asia & 5 \\
\hline Southeast Asia & 6 \\
\hline East Asia & 7 \\
\hline Japan & 26 \\
\hline Europe & 17 \\
\hline Northern Europe & 17 \\
\hline UK & 17 \\
\hline Western Europe & 19 \\
\hline Germany & 21 \\
\hline Eastern Europe & 14 \\
\hline Czech Republic & 17 \\
\hline Southern Europe & 19 \\
\hline Italy & 21 \\
\hline Oceania & 11 \\
\hline Australia & 14 \\
\hline
\end{tabular}

topped $14.8 \%$ with the 2011 census and was growing faster than the overall population. Even the USA, which experiences high levels of immigration and comparably higher fertility levels (particularly amongst some immigrant and ethnic groups) relative to other developed nations, is not immune from population aging (Ortman and Velkoff 2014). As of 2013, $14 \%$ of its population was over 65 , and it is expected to grow to $20 \%$ by 2040 , driven in large part by the aging of its baby boom population. In addition, the older minority US population will grow and will be more ethnically and racially diverse in the coming years. However, differences in life expectancy are 
observed, particularly with respect to both income and education, with lower incomes generally associated with lower life expectancies. However, while Blacks tend to have lower life expectancies than non-Hispanic whites, Hispanics (including low income Hispanics) tend to have longer life expectancies than non-Hispanic whites (Pollard and Scommegna 2013). Even many developing countries, including Mexico, China, Brazil and India, will see an acceleration of aging given declines in fertility levels and slowing population growth rates.

We see the aging of societies illustrated through shifting population pyramids which describe the proportional representation of age cohorts within a society, with high fertility societies having a wider base, reflecting the larger proportion of the young as compared to the old (Fig. 1). Within an aging society, what were formally pyramids are now approaching a more rectangular shape as the share of the young decreases and the share of the old increases. Aging is also observed in the dependency ratio, which is the ratio of people aged 65 and older to people aged 15-64 (i.e., those in the labor force). While problematic given who is defined as in the labor force and who is retired, it does give insight into the relative share of the labor force and the retired, and provides a comparator over a number of decades. In Europe, the ratio is projected to double by 2050, meaning that Europe will move from four workers per retired person to just two workers. Currently, the US dependency ratio is approximately 21 and is expected to climb rapidly to 35 by 2013 as baby boomers retire, before slowing its increase (Vincent and Velkoff 2010).

Although aging is a national phenomenon, regions will experience it differently (Kim and Hewings 2013). In general, large metropolitan areas in the USA tend to age faster than the nation as a whole, and domestic migration will be the most important determinant of state and local aging profiles, particularly at more local scales where population movement has the ability to quickly alter population profiles. The migration of seniors is certainly well researched: streams and counter-streams, cyclical or seasonal movements and long-term relocation are common themes within the migration literature (i.e., McHugh et al. 1995; McHugh and Mings 1996). We know that transitions between life stages can trigger major changes in attitudes toward living arrangements, location and neighborhood, prompting migration. For instance, compared with families and younger individuals, people aged 60 and over prefer having walking access to services (Burda 2012), and a Canadian study suggested that a large proportion of baby boomers wished to relocate at retirement (BMO Retirement Institute 2011). Given that boomers tend to be wealthier and more mobile than previous cohorts suggests that migration amongst seniors is an important dimension of population aging that must be considered by policy makers given implications for future housing demand, urban planning, health planning and other policy issues. Indeed, faced with declining or aging populations, some communities have tried to market themselves as retirement destinations, highlighting their natural amenities (Kupiszewski et al. 2001a), lower housing costs and lower taxes (Karner and Dorfman 2012) and the availability of health-related services (Kupiszewski et al. 2001a,b; Kawase and Nakazawa 2009).

State, regional or metropolitan scales will see different impacts associated with aging, reflecting differentials in the level of human capital, the rate of change in human capital and differences in regional economies. From a purely demographic perspec- 


\section{United States, 2015}

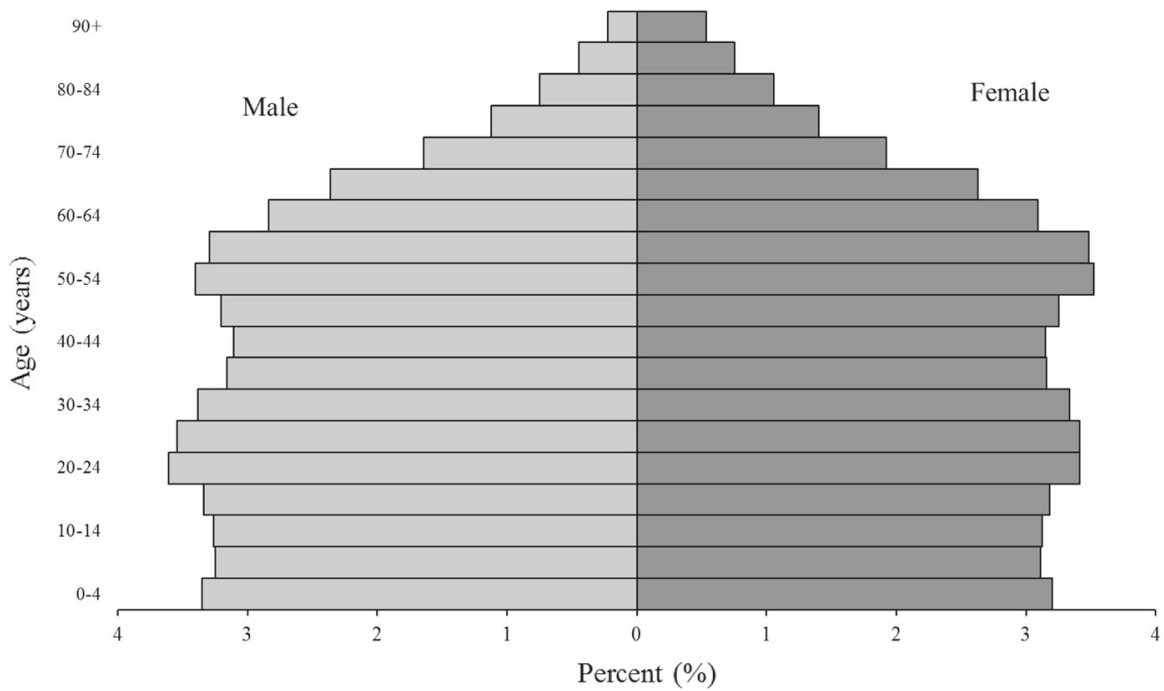

Netherlands, 2015

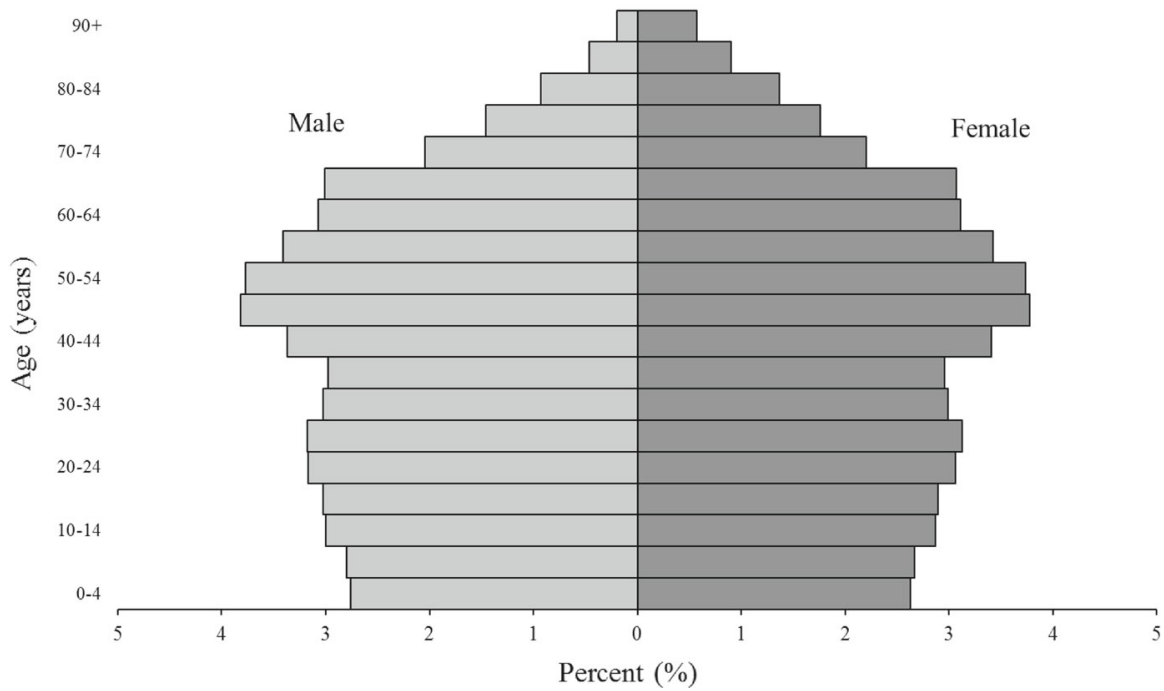

Fig. 1 Population pyramids of the USA and Netherlands, 2015. The US pyramid is more rectangular, reflecting lower fertility. The pyramid for the Netherlands clearly shows a bulge amongst those aged 40+ and a narrowing base

tive, areas experiencing the fastest growth of the $65+$ cohort in the USA are located in the Sun Belt. With $17.4 \%$ of its population aged 65 or greater, Florida is demographically the 'oldest' state. More generally, states with the highest concentrations of seniors are located in the northeast and midwest, partially reflecting deindustrialization and the impact of youth out-migration and seniors aging in place (see, for 
example, Morrill 1995). Conversely, the west and southwest tend to have younger population profiles, thanks to the growth of these economies along with immigration and domestic migration. The resulting political implications are significant: Younger and growing populations in the west and south have resulted in an increasing number of seats in the House of Representatives (Mather 2009).

Reflecting aging at the state level, rapidly aging metropolitan areas are also found in the northeast and midwest. Places such as Youngstown, Scranton, Pittsburgh and Buffalo-old industrial cities - tend to have larger proportions of seniors. Younger metropolitan areas are typically in the south and southwest. But metropolitan areas that are typically considered to be 'young' also have well-established older populations (Frey 2001). Cities, including Las Vegas, Phoenix, Orlando, Denver, Atlanta and Tucson, the host city for the 2015 WRSA meetings, have healthy older populations. It is not, however, that older migrants are necessarily flooding into these centers or that these are retirement destinations. Instead, much of the growth of the older population comes from aging in place. $^{2}$

The geography of aging is impacted by the migration of the old. Dave Plane's work shows the movement of older individuals and empty nesters-people who are relatively footloose - all the way down the metropolitan hierarchy as they transition into retirement-leaving America's largest cities and moving to micropolitan or rural areas (Plane et al. 2005; Plane and Jurjevich 2009). Moreover, these are demographically 'effective' streams - migration in this age group is spatially one way. Of course, what we are witnessing is retiree's preferences for less congestion, greater amenities and lower costs of living. Much of this movement actually occurs amongst the comparatively young elderly, with Plane and Jurjevich (2009) speculating that empty nesting is responsible for the re-evaluation of where to live. Similar evidence is observed in other countries, with movement down the urban hierarchy (Newbold 2011), along with the movement of older, pre-retirement households relocating to more rural areas despite the relocation necessitating a much longer commute to work, suggesting that people were preparing for retirement and establishing themselves in a new environment even before retirement (Axisa et al. 2012).

Movement amongst the old is more than a unidirectional movement down the urban hierarchy, but instead often reflects a series of moves. The younger elderly may be able to use the equity in their homes to finance moves to amenity areas (Graves 1979; Graves and Waldman 1991; Mueser and Graves 1995). Amongst the oldest elderly, there is evidence of return movements up the settlement hierarchy to places including medium urban areas (Plane and Jurjevich 2009). Often times, these migrations occur for health reasons or need to be near family for support as health starts to decline, with earlier work by Litwack and Longino (1987) describing a typology of moves. Although not necessarily sequential, the young elderly will undertake lifestyle-oriented migrations, typically initiated at or near retirement and frequency motivated by amenities, cost of living or housing considerations. Migrants also tend to be in good health. With increasing age, migrations are typically motivated by the need for assistance

\footnotetext{
2 For a map of aging in the USA (including the state and county scale), see: Howden LM, Meyer JA. 2011.
} Age and Sex Composition, 2010. 2010 Census Briefs, US Census Bureau, C2010BR-03. 
along with the desire to be closer to family for support as personal health declines. Finally, the third migration in later life is often into institutions providing long-term care.

Migration of the old tends to reflect amenities and to focus on a handful of destinations, including Florida, California and Arizona. At smaller spatial scales, migration may create retirement communities-Arizona and Florida have an abundance of these - and the inflow of seniors reflects their desire to share in the amenities of a locale. This amenity-lead migration is a large driver of economic activity in places such as the American Mountain-West (Chipeniuk 2005). Conversely, communities that either lose their young labor force members or young and healthy old are left with an increasingly aged population that may strain resources or require new resources and services to deal with their growing elderly population.

Drilling further down into the geography of aging, we see differential spatial patterns within metropolitan areas, with a growing share of elderly households in suburbia, reflecting the fact that boomers tend to be more suburbanized than other age groups, and resulting in a greying of suburbia. This trend is set to accelerate as boomers retire unless there are dramatic shifts in location preferences à la Alonso (1978), such as new retirees trading their suburban bungalows for downtown environments or other urban areas (see, for example, Kim 2011a; Warnes and Ford 1995).

But could the movement of the old out of large cities and down the urban hierarchy result in a new geography of cities, one that in turn results in the relocation of services to these smaller centers as explored by Gaigné and Thisse (2009)? This return to the 'Rentier City,' is reflected in arguments made by Krugman (2007) whereby cities in the not so distant future would look more like pre-industrial cities characterized by an economic base that is driven by people - the retired elderly-whose income comes from elsewhere. In exploring this hypothesis, Gaigné and Thisse (2009) did not find evidence of a return to an earlier time, largely because large urban areas will retain services, with urban effects preventing services from relocating and following the old out of the cities.

It is also important to note that the overwhelming tendency amongst seniors is not to move. Instead, most 'age in place,' with one study finding that $89 \%$ of Americans want to stay in their own homes as they age, or at least stay in their immediate community (Davis 2013). While this contradicts an earlier argument that most seniors would like to move, the devil is in the details, including how questions regarding preferences were asked, along with the economic and social reality that comes with relocation. In other words, it is safe to assume that most of the old will not relocate. Places that will have a large growth of seniors are therefore places where there is already a large 'pre-senior' population, such as those aged 55-64. Sunbelt places have large numbers of these pre-seniors, so will experience a rapid growth of the elderly. The growth of the old in these Sunbelt destinations will reflect the growth of 'NORCS,' or Naturally Occurring Retirement Communities, reflect those places where seniors age in place. But for the majority of seniors, they will stay where they are, implying that services will stay as well, but necessitating further insight on what this means for urban areas and systems as they deal with the economic and demographic implications of a growing older population. 


\section{Where does regional science fit?}

Where does regional science fit in? To date, there is a relative lack of research by regional scientists that addresses population aging. It is not that we as regional scientists are not looking at the effects of an aging population, and several researchers have been noted above. Moreover, regional scientists are certainly capable of a healthy and productive stream of research associated with population issues: If there was ever a group of researchers that was ready to explore the various dimensions of aging, itis regional science. Regional scientists do population studies, spatial analysis, transportation, location/allocation modeling and such and regional scientists $d o$ deal with population aging. But, we could do far more, with future research potentially considering the following aspects of aging:

1. Spatial scale The literature associated with aging populations from a national perspective is large. But aging is not just a national phenomenon, but one experienced at every spatial scale, from the national level down to the local. Despite the large volume of national-level findings, the results may not translate to the local or regional scale (Kim and Hewings 2013). Likewise, results of national policy change may not apply at the regional level given variations in economic and demographic structures (Park and Hewings 2007b). In particular, understanding the role of spatial scale may be particularly acute in rural areas or small towns, where population size, financial abilities, human capital, and limited housing and transportation can make it difficult to respond to aging populations (Hallman et al. 2008). I would suggest that Regional Scientists can assist here.

It is at the neighborhood, community and regional scales where population aging is most experienced, often times owing to differential migration flows that change the age structure of the population. More importantly, much of the work on aging is disparate, and there is a need to view aging from a spatial perspective. There is a need, as Gerald Hodge notes, to have 'micro' and 'macro' perspectives and to 'understand the everyday lives of seniors and the geography they generate' (Hodge 2008, p. 221). That is, we need to know where the elderly live and the spatial pattern of their activities, as well as the larger-scale picture, and we need to be able to seamlessly transition across scales.

We need to be careful, however, to not just focus on the western, developed world given that many countries in the developing world are also moving through demographic transitions and experiencing lower fertility rates. David Plane (2012, p. 479), for instance, suggests that:

Regional scientists are perfectly positioned to provide insights about the regional repercussions of demographic "aging" conceived not just as increases in elderly dependency but rather in terms of the entire dynamic adjustment process attendant with the rapid demographic transitions taking place throughout the former Third World.

Given the tools that we as regional scientists have at our disposal, we are particularly adept at moving between spatial scales and demonstrating the links between them. 
2. Migration Although to list the names of regional scientists that have contributed to the migration and immigration literatures will mean that someone is left out, regional scientists including Alonso, Clark, Cooke, Cushing, Greenwood, Plane, Rogers, Rogerson, Waldorf and others have a long and solid tradition of migration studies that account for age and age effects. Aging and increased life spans will undoubtedly have implications for migration patterns and trends in the USA and elsewhere. Coupled with industrial loss and depending on who moves, along with the number of migrants, out-migration could have important implications for service delivery, economic development and planning. For example, the selective out-migration of workers along with relatively healthy and wealthy new retirees can leave behind an older, poorer and less healthy population, with implications for service delivery and the fiscal capacity of communities (Davenport et al. 2009), while services geared toward younger cohorts, including schooling, will be forced to close. Consequently, there is a need to better understand the impacts of migration and what this means for communities. Can communities reduce out-migration and how is this done? Amongst communities that have lost younger workers, who pays for services and how can they provide services and care for their residents? How does migration of the older population shift income into or out of communities (i.e., Nelson 2005)?

The age-migration schedule (Rogers et al. 1978) is a well-established phenomenon that highlights regularities in-migration rates as individuals age, hinting at the role that the life course status has for migration choices (Goetzke and Rave 2013; Plane and Jurjevich 2009). For example, increasing life expectancy changes the time frame over which migrations can occur and when care is needed. Destination choices, and indeed the decision to migrate amongst older migrants will likely be influenced not just by where they came from or grew up, but also by where their adult children are and whether these adult children have moved up or down the hierarchy and across the country, along with their need for health care, reflecting their own point in the life course along with other opportunities and needs. Likewise, migration choices of empty nesters may be influenced by the location of their aging parents so that care can be provided. Moreover, several papers have illustrated how diverse older migrations are in terms of both motivations for migration and destinations across the life course (i.e., Clark and Hunter 1992; Whisler et al. 2008). Consequently, additional research is needed on how migrations reflect life course and links between adult children, empty nesters, and the need for care amongst their older parents. How important are ties to place? How important and strong are settlement preferences? Will observed patterns continue in the coming years as the population continues to age or will cohort differences, such as those between 'young' and 'old' boomers result in different migration and settlement patterns?

Communities that have attempted to position themselves as retirement destinations also pose opportunities for regional scientists. As Serow (2003) concluded in a survey of American and Canadian research:

This area of inquiry may be characterized by a paucity of knowledge regarding the longer term effects of retiree migration. There has been no effort to analyze the 
aging in place of the newcomers or the failure of the retirement migration process to generate little more than low-wage service employment.

Serow went on to argue that jurisdictions must 'ensure a continual replenishment of the supply of comparatively young, healthy and affluent retirees' (Serow 2003, p. 901) if they intend to model themselves as retirement destinations. From a regional science perspective, what is the impact of an influx of seniors on the future growth of municipalities? How does the outcome differ from other growth options? Consequently, there is room for research that considers the relative tradeoffs in terms of economic development and the drivers of economic development over both the short- and long-term associated with targeting old versus young migrants.

3. Location/allocation of services relative to population settlement patterns and needs: To reference an over-used quote, the geography of an aging population can be described by 'Location, Location, Location.' Knowledge of its geography is critical to understanding and preparing for the coming decades. Rather than being mobile, the problem is that many of our seniors will age in place in suburban areas. But, these areas are not designed for an aging population.

There are at least two interrelated questions. First, how and where will aging transform these places? Second, how can these locations be adapted to better fit the needs of an aging society? The response(s) go beyond the number of seniors, and includes housing, activity, travel, quality of facilities and the availability of services. All of these are spatial in nature. Embedded here is the concept of activity space(s) of the elderly and how these change in response to aging, the physical environment, and personal and community resources. For regional scientists, therefore, answering these questions requires a number of different research directions. First, there is a need for better measures / indices of aging to capture the relationship between the older population and those in the labor force-dependency ratios do not work. Second, how will the changes in the age structure of a region alter what is consumed as well as what is produced? Or, perhaps more concisely, what are the changes in expendables as households' age? This includes housing, health care and other services.

4. Transportation Given that baby boomers have grown up with the car, and in many cases, the car defines them, we tend to assume that the car will remain their preferred transportation mode choice. The reality, however, is less clear. Yet for the elderly, the sprawling structure of many of our metropolitan areas, the continued dependency on the personal automobile and limited use of public transit by the elderly challenges the mobility and accessibility of the old (Collia et al. 2003; Miller et al. 2007; Turcotte 2012). An increasingly large number of our old will not have a driver's license, having given them up for health or other personal reasons. Moreover, aging at home becomes difficult for individuals who are no longer able to drive if a car is their only available means of transportation, particularly for older females who typically face greater transportation barriers and mobility problems than males given that they are more likely to live longer, more likely to live alone and are less affluent than male counterparts (Kim 2011b). Aging at 
home is also a greater burden for those in rural areas or areas poorly served by transportation alternatives.

In part, this implies that the transportation needs and behaviors of the old are likely more heterogenous than what the literature currently identifies, which has tended to see the old as a somewhat monolithic group simply aged 65 plus. Questions might include whether older workers (i.e., those older than 65) have commute patterns that differ from younger workers, with these older individuals potentially more willing to commute longer distances and perhaps making trade-offs with location (i.e., Axisa et al. 2012). Other questions must consider what happens when people get too old to drive? How does the built environment and transport options affect their own choices and subsequently quality of life? How can other principles such as universal design and age-friendly communities be included within transportation agendas? Such questions may be even more important in rural locations, small towns or even suburban settings that tend to be more auto-oriented and where transport options are more limited (Hallman et al. 2008). Once again, regional science includes a significant number of people engaged in transportation research, but how well do we understand the transportation needs of the old?

5. Planning Although amenity-driven migration is significant, there is limited systemic planning for it, with the exception of the broad goal of attracting retirees. Planning for an aging population should include planning for age-friendly communities, transportation and other needs. In addition, if communities want to position themselves as recipients of older migrants, analysis of amenity migration should include tools for understanding motivations for migration to these areas and for understanding related effects, including real estate, housing, transportation and other services (Chipeniuk 2005; Tompkins 2008). Planning for an aging population requires identifying program and service priorities, which requires research and an understanding of community demographics and the needs of the seniors, tools which are commonly used by Regional Scientists. At smaller spatial scales, state and local social services and infrastructure needs will also change with the aging of the population. Consequently, the age structure and demographic importance of the senior population in a community will have an important impact on municipal services, given that the range of community services that people require after they retire differs from that during other stages of life.

6. Economic analysis We know that population aging will challenge economies, social welfare/healthcare systems, social welfare systems and labor markets. Regional scientists, and particularly work by Geoff Hewings and his colleagues, have made substantial contributions to the understanding of the economic implications of an aging population. Work by Hewings and colleagues at the Chicago regional level, for example, project a decline in gross regional product (GRP) due to the aging population, a shrinking labor force and reduced savings. Likewise, a larger proportion of elderly relative to the labor force may equate with slower economic growth as individuals move to less productive roles and household expenses are put toward less productive purposes and reduced spending (Yoon and Hewings 2006). Of course, the in-migration of younger workers can offset declines in GRP (Park and Hewings 2007a), at least at the regional scale, while immigration could offset problems at the national scale. 
Despite the work by Hewings and other Regional Scientists, questions remain, including the impact on productivity and economic growth, as well as saving and expenditures. In the former case, the loss of the working age population could have a significant impact on per capita income, unless the loss of labor can be compensated through other means, such as increasing productivity (Park and Hewings 2007a). But how can productivity be increased over time and can it be increased given an aging population? In the latter case, savings and expenditures could change as populations age (Wakabayashi and Hewings 2007). Given that many baby boomers are heading into retirement carrying a larger debt load than previous generations, with higher debt loads encouraged by low interest rates and a culture of spending, what are the implications for consumer spending and saving, and how will this translate into economic growth and opportunities?

\section{Conclusions}

As regional scientists, we need to pay greater attention to the role of age and aging in our research. Population aging will have significant effects on local, regional and national economic systems and policies, with regional scientists uniquely situated to add considerable depth and breadth to the advancing discussions. This is not to say that significant amounts of research on aging are not going on in a broad variety of fields - it is just that regional scientists have been less fully engaged with the topic. I echo a comment from David Plane that we have 'paid insufficient attention to aging' (Plane 2012, p. 475). Population aging poses significant challenges for communities, regions and states, with important differences by race, ethnicity and income status, meaning that there are equally a large number of academic questions that we as regional scientists can engage.

But in recognizing what regional scientists can add to the research agenda, it is important to keep in mind two final points. First, aging, like regional science, is multi-dimensional, meaning that different research agendas within the aging paradigm cannot be seen in isolation. We cannot, for example, adequately address housing issues amongst the old without considering access to transportation. Given that many of our suburbs are not equipped to deal with an aging population - they tend to make individuals dependent on their cars and lack services and stores that are accessible through short trips - transportation is key, as is the actual location of the service or store. Once again, regional scientists have the tools and knowledge to consider these problems from multiple dimensions. Moreover, given the scope of the problem, a comprehensive analysis will require a multi-sectoral analysis - across housing, transportation, economic development, social services, health services, recreational services - of the interaction amongst multiple factors, meaning that opportunities exist not just for individual research, but for interdisciplinary work.

Second, an outcome of the research agenda should be expressed through contributions to the policy agendas. How will aging transform policy? How will places transform to meet the needs of an aging population and what knowledge can regional science impart? Regional scientists should be encouraged to publish in policy-oriented journals including Regional Science Policy \& Practice, as well as other policy related 
journals. But, more precisely, we have the ability (and obligation) to engage discussions related to transportation, economic development, location of services and age-friendly communities.

\section{References}

Alonso W (1978) A theory of movements. In: NM Hansen (ed) Human settlement systems: international perspectives on structure, change and public policy. Ballinger, Cambridge, pp 197-211

Axisa J, Newbold KB, Scott DM (2012) Migration, urban growth, and commuting distance in Toronto's commute shed. Area 44(3):344-355

BMO Retirement Institute (2011) Where do Canadians plan to retire, and why? Special report. Bank of Montreal, Toronto. https://www.bmo.com/pdf/mf/prospectus/en/BMO_Retirement_Institute\%20Report_ En.pdf. Accessed 14 April 2015

Burda C (2012) RBC-Pembina home location study: understanding where greater Toronto area residents prefer to live. Pembina Institute, Toronto

Chipeniuk R (2005) Planning for rural amenity migration. Plan Can 45(1):15-17

Clark DE, Hunter WJ (1992) The impact of economic opportunity, amenities and fiscal factors on age specific migration rates. J Reg Sci 32:349-365

Collia DV, Sharp J, Giesbrecht L (2003) The 2001 national household travel survey: a look into the travel patterns of older Americans. J Saf Res 34:461-470

Davenport J, Rathwell T, Rosenberg MW (2009) Aging in Atlantic Canada: service-rich and service-poor communities. Healthc Policy 5(1):145-160

Davis LS (2013) Aging in place suburban style. J Am Plan Assoc 79(6):24-28

File T (2014) Young-adult voting: an analysis of presidential elections, 1964-2012. US Census Bureau P20-573. https://www.census.gov/prod/2014pubs/p20-573.pdf. Accessed 9 June 2015

Frey W (2001) The baby boom tsunami. The Milliken Institute Review http://www.frey-demographer.org/ briefs/B-2001-5_BabyBoomTsunami.pdf. Accessed 8 April 2015

Gaigné C, Thisse J-F (2009) Aging nations and the future of cities. J Reg Sci 49:663-688

Goetzke F, Rave T (2013) Migration in Germany: a life cycle approach. Int Reg Sci Rev 36(2):167-182

Graves PE (1979) A life-cycle empirical analysis of migration and climate, by race. J Urban Econ 6:135-147

Graves PE, Waldman DM (1991) Multimarket amenity compensation and the behavior of the elderly. Am Econ Rev 81:1374-1381

Green B (2006) Marketing to leading-edge baby boomers: perceptions, principles, practices, predictions. Paramount Market, New York

Hallman B, Menec V, Keefe J, Gallagher E (2008) Making small towns age-friendly: What seniors say needs attention in the built environment. Plan Can 48(3):18-21

Hodge G (2008) The Geography of aging: preparing communities for the surge in seniors. McGill-Queens University Press, Montreal

Ibbitson J (2014) A bleak future and population crisis for South Korea. The Globe and Mail, October 22, 2014, p A4. http://www.theglobeandmail.com/news/world/a-bleak-future-and -population-crisis-for-south-korea/article21249599/. Accessed 8 April 2015

Karner A, Dorfman J (2012) Retiree migration: considerations of amenity and health access drivers. Presented at the annual meeting of the Agricultural and Applied Economics Association, August 12, Seattle

Kawase A, Nakazawa K (2009) Long-term care insurance facilities and interregional migration of the elderly in Japan. Joint discussion paper series in economics, no. 39. MAGKS Network of the Universities of Aachen, Giessen, Göttingen, Kassel, Marburg and Siegen

Kim S (2011a) Intra-regional residential movement of the elderly: testing a suburban-to-urban migration hypothesis. Ann Reg Sci 46(1):1-17

Kim S (2011b) Transportation alternatives of the elderly after driving cessation. Transp Res Rec 2265:170176. doi: $10.3141 / 2265-19$

Kim T-J, Hewings GJD (2013) Endogenous growth in an aging economy: evidence and policy measures. Ann Reg Sci 50(3):705-730

Krugman P (2007) Return of the rentier city. The New York Times, October 5, 2007 
Kupiszewski M, Illeris S, Durham H, Rees P (2001a) Internal migration and regional population dynamics in Europe: Denmark Case Study. Working paper. University of Leeds, School of Geography, Leeds

Kupiszewski M, Borgegard L-E, Fransson U, Hakansson J, Durham H, Rees P (2001b) Internal migration and regional population dynamics in Europe: Sweden Case Study. Working paper, University of Leeds, School of Geography, Leeds

Litwack E, Longino CF (1987) Migration patterns among the elderly: a developmental perspective. Gerontologist 27:266-272

Long L (1988) Migration and residential mobility in the United States. Russell Sage Foundation, New York

Mather M (2009) States in the west and south are set to gain political clout. http://www.prb.org/Publications/ Articles/2009/apportionment.aspx. Accessed 9 June 2015

McHugh KE, Hogan TD, Happel SK (1995) Multiple residence and cyclical migration: a life course perspective. Prof Geogr 47(3):251-267

McHugh KE, Mings RC (1996) The circles of migration: attachment to place and aging. Ann Assoc Am Geogr 86(3):530-550

Morrill R (1995) Aging in place, age specific migration and natural decrease. Ann Reg Sci 29(1):41-66

Mueser PR, Graves PE (1995) Examining the role of economic opportunity and amenities in explaining population redistribution. J Urban Econ 37:1-25

Miller G, Harris G, Ferguson I (2007) Bracing for the demographic tsunami: How will seniors fare in an aging society? Plan Can 47(4):20-21

Newbold KB (2011) Migration up and down Canada's urban hierarchy. Can J Urban Res 20(1):131-149

Nelson PB (2005) Migration and the regional redistribution of nonearnings income in the United States: metropolitan and nonmetropolitan perspectives from 1975 to 2000. Environ Plan A 37:1613-1636

Newbold KB (2005) Spatial scale, return and onward migration, and the Long-Boertlein index of repeat migration. Pap Reg Sci 84(2):281-290

Ortman JM, Velkoff VA (2014) An aging nation: the older population in the United States. US Census Bureau, New York

Pollard K, Scommegna P (2013) The health and life expectancy of older Blacks and Hispanics in the United States. Today's Research on Aging 28. Population Reference Bureau

Park S, Hewings GJD (2007a) Aging and the regional economy: simulation results from the Chicago CGE model. Discussion paper 07-T-4, Regional Economics Applications Laboratory, University of Illinois, Urbana IL. www.real.uiuc.edu. Accessed 8 April 2015

Park S, Hewings GJD (2007b) Immigration, Aging, and the Regional Economy. Discussion Paper 07-T-5, Regional Economics Applications Laboratory, University of Illinois, Urbana, IL. www.real.uiuc.edu. Accessed 8 April 2015

Plane DA (2012) What about aging in Regional Science? Ann Reg Sci 48:469-483

Plane DA, Henrie CJ, Perry MJ (2005) Migration up and down the urban hierarchy and across the life course. PNAS 102(43):15313-15318

Plane DA, Jurjevich JR (2009) Ties that no longer bind? The patterns and repercussions of age-related migration. Prof Geogr 61(1):4-20

Rogers A, Racquillet R, Castro LJ (1978) Model migration schedules and their applications. Environ Plan A 10:475-502

Serow WJ (2003) Economic consequences of retiree concentrations: a review of north American studies. Gerontologist 43(6):897-903

Taber J (2012) Rural Nova Scotia faces demographic reality of elderly, declining population. The Globe and Mail, May 28. http://www.theglobeandmail. http://www.theglobeandmail.com/news/national/ rural-nova-scotia-faces-demographicreality-of-elderly-declining-population/article4217036/. Accessed 14 April 2015

Tompkins L (2008) Planning for the seniors surge —one municipality’s response. Plan Can 48(3):30-33

Turcotte M (2012) Profile of seniors' transportation habits. Canadian Social Trends, Statistics Canada Catalogue no 11-008

Vincent GK, Velkoff VA (2010) The next four decades: the older population in the United States: 2010 to 2050. US Census Bureau

Wallace P (2001) Agequake: riding the demographic rollercoaster shaking business, finance, and our world. Nicholas Brealey, London

Wakabayashi M, Hewings GJD (2007) Life cycle changes in consumption behavior: age-specific and regional variations. J Reg Sci 47(2):315-337 
Warnes AM, Ford R (1995) Housing aspirations and migration in later life: developments during the 1980s. Pap Reg Sci 74(4):361-387

Whisler RL, Waldorf BS, Mulligan GF, Plane DA (2008) Quality of life and the migration of the college educated: a life-course approach. Growth Change 39:58-94

Yoon SG, Hewings GJD (2006) Impacts of demographic changes in the Chicago Region. Discussion paper 2006-07-T-6, Regional Economics Applications Laboratory, University of Illinois, Urbana. www.real. uiuc.edu. Accessed 8 April 2015 